\title{
3D DOCUMENTATION OF FRAIL ARCHAEOLOGICAL FINDS USING LOW-COST INSTRUMENTATION
}

\author{
V. Katsichti ${ }^{1}$, G. Kontogianni*2 ${ }^{2}$ A. Georgopoulos ${ }^{2}$ \\ ${ }^{1}$ Department of Mediterranean Studies, University of the Aegean \\ vkatsihti@gmail.com \\ ${ }^{2}$ Laboratory of Photogrammetry, School of Rural and Surveying Engineering, National Technical University of Athens \\ 15780 Zografou Athens, Greece \\ (gkondog, drag)@central.ntua.gr
}

\section{Commission II}

KEYWORDS: Image-Based modelling, Fresco fragments, Conservation, Foldio 360

\begin{abstract}
:
In archaeological excavations, many small fragments or artefacts are revealed whose fine details sometimes should be captured in 3D. In general, 3D documentation methods fall into two main categories: Range-Based modelling and Image-Based modelling. In Range Based modelling, a laser scanner (Time of Flight, Structured light, etc.) is used for the raw data acquisition in order to create the 3D model of an object. The above method is accurate enough but is still very expensive in terms of equipment. On the other hand, ImageBased modelling, is affordable because the equipment required is merely a camera with the appropriate lens, and possibly a turntable and a tripod. In this case, the 3D model of an object is created by suitable processing of images which are taken around the object with a large overlap. In this paper, emphasis is given on the effectiveness of 3D models of frail archaeological finds originate from the palatial site of Ayios Vasileios in Laconia in the south-eastern Peloponnese, using low-cost equipment and methods. The 3D model is also produced using various, mainly freeware, hence low-cost, software and the results are compared to those from a well-established commercial one.
\end{abstract}

\section{INTRODUCTION}

Digital technological advancements and 3D modelling in particular, have offered new and alternative perspectives in archaeological research. Many disciplines concerned with Cultural Heritage, such as archaeologists, architects, conservators to name but a few, are using -with varying degrees of success and competence- contemporary automated image-based modelling software to produce digital models of the objects of their interest. However, this has many pitfalls, as very often the mechanism behind this automation is not known, which results to inability to evaluate the seemingly impressive results. In addition, the term Digital Cultural Heritage is spreading fast, although it really as no core meaning. In this paper an interdisciplinary approach for producing useful $3 \mathrm{D}$ models of fragile fresco fragments is presented and a first evaluation of low-cost freeware software is also attempted.

\section{3D DOCUMENTATION OF SMALL ARTEFACTS}

Recently, many attempts have been reported concerning the 3D documentation and modelling of small artefacts using various methods or approaches. Ritz et al. (2011) developed a structured light system which employs a low-cost camera projector. Koutsoudis et al. (2013) used image-based modelling to 3D digitise a small Cycladic female figurine for evaluating the performance of commercial SfM-MVS software. The 3D model of two lekythoi was created with the use of a structured light system by XYZRGB consisting of two machine vision cameras for the determination of the geometry of the artefact, a high-resolution camera for the texture and a DLP projector (Soile et al. 2013). Guidi et al. (2014) used preprocessing techniques for enhancing image-based modelling procedure. Especially they utilised polarizing filters, High Dynamic Range Imaging (HDRI) in cases of "difficult" materials presenting shiny or dark etc. surfaces). Nicolae et al. (2014) used image-based modelling on museum artefacts especially in cases that artefacts had been constructed with reflective or absorbent materials, with textureless surface and complex geometry. Hosseininaveh et al. (2014) created a system which brings together different systems and tools into a unique platform to 3D document complex artefacts with high accuracy. The procedure was performed via generating the model of an object by designing a stereo imaging network for the object with this model. Images were captured by exploiting an inverse kinematic method for a non-standard six degree of freedom robot. Noise function patterns were used for enhancing the procedure of 3D reconstruction of featureless surfaces (Koutsoudis et al. 2015). 3D models of ancient Greek inscriptions were created via two approaches: Structured light system and image-based modelling and the results were also evaluated based on the capability of revealing damaged or hidden letters (Papadaki et al. 2015). Low-cost hardware was created by Gattet et al. (2015) with the use of second-hand parts (turntable, stepper motor). A low-cost and portable system was developed for 3D modelling of objects which have a textureless surface (Hosseininaveh et al. 2015). Specifically, this system includes an automated rotating table with a stepper motor. Also, it has laser light sources for supplying an appropriate pattern on textureless surfaces. Sapirstein (2017)

\footnotetext{
* Corresponding author
} 
developed a system for 3D documentation of small artefacts of $5-10 \mathrm{~cm}$ approximately in size. This system consists of a turntable on which the object is positioned while it is illuminated with artificial lighting coming from a ring-flash mounted on the lens. The ORION (arduinO Raspberry pI rOtating table for image-based $3 \mathrm{D}$ reconstructioN) is an image-based acquisition hardware and software system for the 3D documentation of small size objects (Menna et al. 2017). Lachat et al. (2017) performed different experiments covering various topics e.g. influence of colour's range, achieved precision for geometrical primitive digitisation by utilising a handheld 3D scanner applied in small artefacts. A triangulation scanner was used for the 3D digitisation of a small archaeological finding (Ballarin et al. 2018). The produced 3D model was printed in $3 \mathrm{D}$ via different $3 \mathrm{D}$ printers and final $3 \mathrm{D}$ replicas were compared. The system was connected with 3 DSLR cameras and was controlled with Arduino microcontroller. Marshall et al. (2019) developed a novel system concerning digital photogrammetry for the precise 3D reconstruction of small museum artefacts. Also, a Structured light system was used for the digitisation of the walking system of dinosaurs (legs, foot) in order to perform investigations through the Finite Element Method (FEM) (Rodriguez Miranda et al. 2019). Image and Range-based methods were used for 3D documentation of small artefact for investigating the material, the colour and the complexity of the object's surface (Evgenikou \& Georgopoulos 2015). Museum artefacts are digitised in 3D with the use of images in order to create a replica of them via 3D printing technology (Fregonese et al. 2019). Macro photogrammetry was used in many applications for 3D documentation of small size objects (Angheluță \& Rădvan, 2019; Gajski et al. 2016). Also in the case of macro photography a Computational photography technique, focus stacking was utilised in case of studies for enhancing the 3D documentation of artefacts in cases of restricted DoF (Clini et al. 2016; Gallo et al. 2013; Kontogianni et al. 2017a; Kontogianni et al. 2017b). Attempts for enhancing the procedure of $3 \mathrm{D}$ reconstruction of small artefacts was performed with the use of high-quality mirrors (Kontogianni et al. 2018; Kontogianni et al. 2019).

\section{THE ARCHAEOLOGICAL SIGNIFICANCE OF THE ARTEFACTS}

The finds treated in our case are fresco fragments coming from Ayios Vasileios site, near Sparta which is placed in Laconia at the south-east of Peloponnese, Greece. The site of Ayios Vasileios is been systematically excavated since 2010 under the directorship of Mrs. A. Vasilogamvrou and the auspices of the Archaeological Society at Athens. The investigation at the site revealed archaeological remains of great importance which indicate the prosperity of a significant administrative centre of the Mycenaean period (1500-1300 BC). Among other important finds, such as Linear B tablets, a significant amount of fresco fragments were unearthed in different deposits on the hill. The fragments are not yet connected with any of the architectural remains. The iconographic themes attested are typical of the wall paintings of the Mycenaean period. (PAE, 2010). For the present study, four fragments were selected (Figure 1): (1) Sample S8 depicting a floral motif (max. dim. $8 \times 4,7 \mathrm{~cm}$ ), (2) Sample S10 also depicting plant motif (max. dim. 10,2 x 8,8cm), (3) Sample S38 depicting a female face in profile in an architectural structure (max. dim. $9 \times 7,2 \mathrm{~cm}$ ) and (4) Sample S52 depicting a male foot (max. dim. 5,7 x 4,7cm).

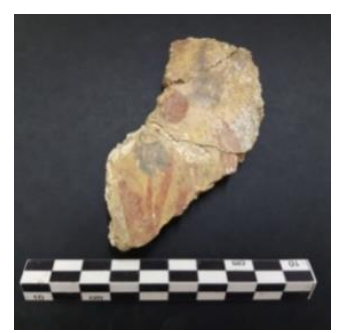

Sample S8

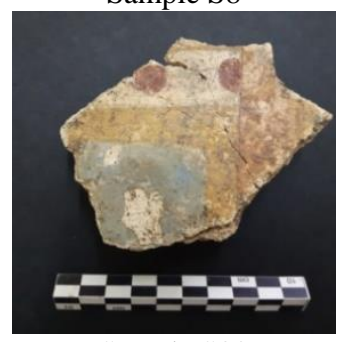

Sample S38

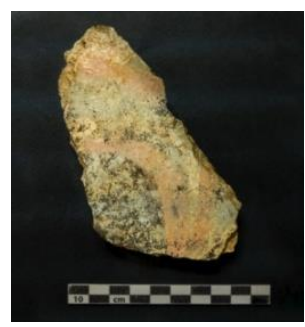

Sample S10

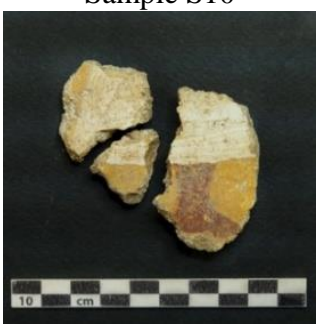

Sample S52
Figure 1The four samples used

Due to the high archaeological and artistic value of the fresco fragments and their state of preservation, a non-destructive approach was followed by documenting them with 3D digitization. A 3D digital artefact, not only gives the experts the option of contactless study but also provides further insight into the artistic and manufacture techniques.

\section{EXPERIMENTAL SETUP}

For the precise and reliable 3D documentation of the Mycenaean fresco fragment, the Foldio $360^{\circ}$ system was employed (Foldio 360, 2019). This system consists of an automated turntable located inside a lightbox with stable LED lighting. The turntable is controlled by a smartphone with the help of the Foldio 360 application which is available for free for Android and IOS devices. The rotation step was set to 10 degrees, which is a common rotational distance to simulate the hand-held camera movement around the object. A white circular disc with coded targets was positioned on the turntable for providing scaling possibilities. The distances between the targets were measured with high accuracy using a glass scale ruler (Figure 2).

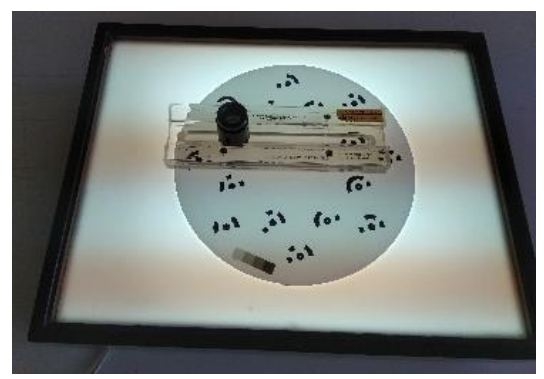

Figure 2: Glass scale ruler

A Canon EOS 6D DSLR camera with a full-frame sensor, fixed on a tripod, with a Canon EF $135 \mathrm{~mm}$ lens providing an $\mathrm{f} / 2$ maximum aperture was utilised. The aperture was set to its smallest possible value $(\mathrm{f} / 32)$ for achieving a greater depth of field (DoF). The shutter speed was set to $1 / 4 \mathrm{sec}$ and the ISO was set 100 to minimize the sensor's noise and no flash was used. Also, the XRite Color Checker Classic (XRite chromatic scale, 2019) was employed for the white balance and for rendering the correct colour. For achieving the above- 
mentioned result, an image was taken with the XRite Color Checker in the field of view before the actual photo shooting of each fragment. A total of 72 images were taken for each fragment. Particularly, 36 images were taken from the painted upper surface and 36 for the bottom side. Figure 3 presents the experimental setup. For some fragments, it was necessary to create a $3^{\text {rd }}$ loop of images taken from different height in order to capture correctly in detail the complexity of the relief of the back part.

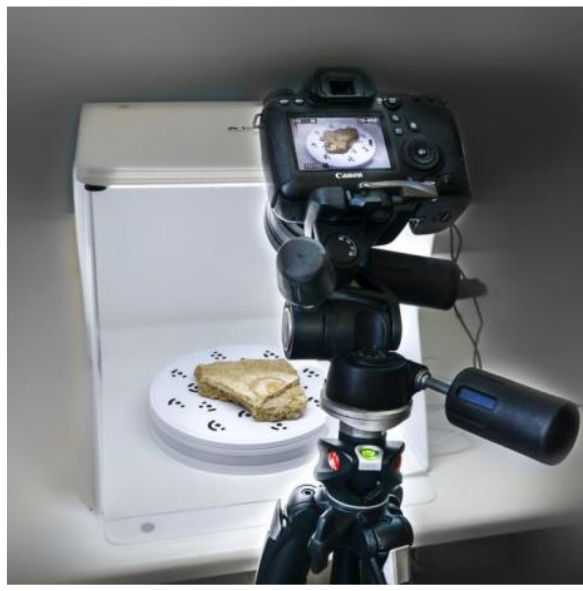

Figure 3: Experimental setup

\section{3D MODELS CREATION}

\subsection{Commercial Software}

The image data for the creation of 3D models were firstly processed by using Agisoft PhotoScan Professional (64bit) v.1.4.0 software. The workflow steps involved in the construction of the texture $3 \mathrm{~d}$ models are the following. Firstly the image sets were subjected to radiometric enhancements, no geometric transforms were performed and the poorly focused images were excluded from processing. Once each set of photos was loaded into PhotoScan, it needed to be aligned in order to build a sparse point cloud. At this stage, in our case, PhotoScan failed to find the correct camera position and orientation because of the use of the turntable, so the photos were positioned incorrectly (Figure 4).

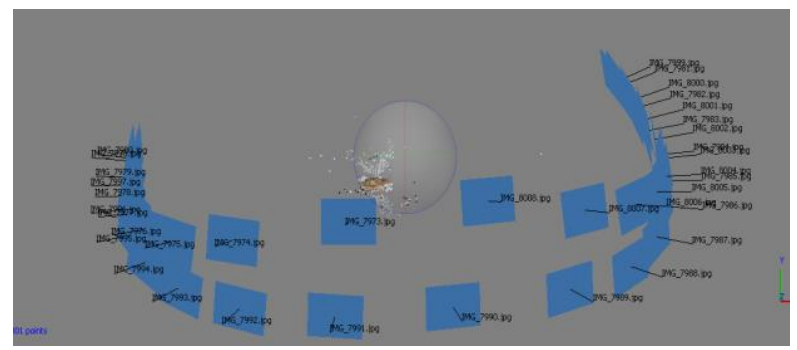

Figure 4: Incorrect alignment of the photos before the masks were used

This problem was solved by applying masks to specify the area of interest in the photo. Subsequently, a dense point cloud was built to the separate chunks of each two image sets and highest quality settings were used to obtain more detailed geometry, despite the longer time needed for processing.

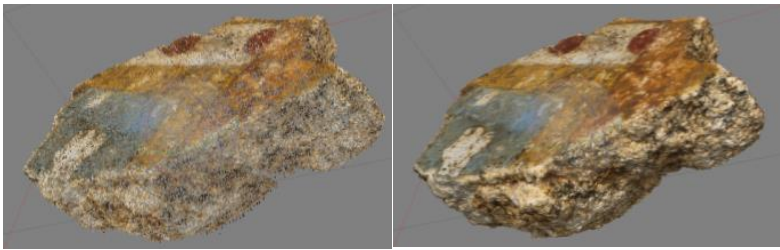

Figure 5: Sparse (left) and dense (right) point cloud of S38 in Agisoft PhotoScan software.

Next step was to set scale bars with accuracy $0,003 \mathrm{~m}$ between the known distance target points, to assign metric information to the model. The total error was between $0,0004 \mathrm{~m}-0,0008 \mathrm{~m}$ which is acceptable because it does not affect the quality of the final product. Scale bars also helped for the correct alignment of the two separate chunks which were merged. The dense point cloud procedure was repeated. Afterwards, the polygonal model mesh was reconstructed. The highest value of the number of triangles was set. Finally, the model texture (Figure 6) was built selecting the default mapping mode, generic.

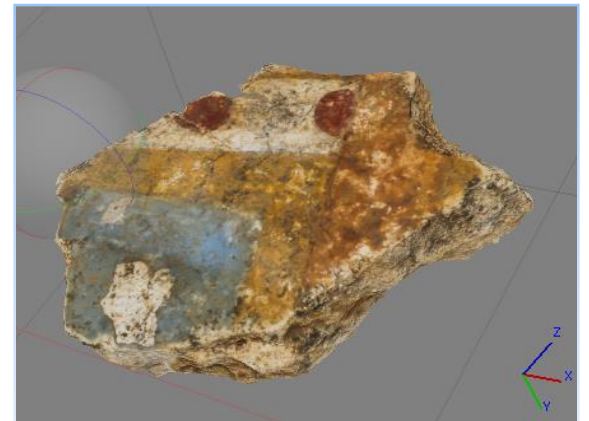

Figure 6: The 3D textured model of the fragment S38

The total time spent reconstructing the 3D models cannot be precisely determined due to the great emphasis on experimentation on how the software responds to different parameter combinations per processing step. The goal was to find the best possible sequence of actions to implement the 3D models.

\subsection{Open-source software}

3D models of one fragment were also created with the use of open-source software (OSS). Many OSS were developed for the creation of 3D models and some of them were used for the 3D model creation: Visual SfM, Regard 3D and COLMAP. These pieces of software were utilised for one fragment which has most of the cases that a conservator would wish to study. The procedure of the above-mentioned freeware is the same. According to the software two point clouds were created: One of the painted upper surface part of the artefact and one for the bottom side.

Visual SfM: is a GUI application for 3D reconstruction using the Structure from Motion (SfM) pipeline (Visual SfM, 2019). The software runs a fast by exploiting multicore parallelism for feature detection, feature matching, and bundle adjustment. For the development of the dense point cloud, the software integrates the execution PMVS/CMVS tool (Furukawa \& Ponce, 2009).

Regard 3D: is a Structure from Motion freeware. It can create 3D models from objects using a series of images taken from different viewpoints around the object (Regard 3D, 2019). The software for detecting keypoints on images uses the A-KAZE algorithm (Alcantarilla et al. 2012). The LIOP (Local Intensity 
Order Pattern) was used by the software for the calculation of a mathematical descriptor for each feature (Wanf et al. 2011). The user may use various algorithms for the dense point cloud generation. Also, the mesh of the object can be generated COLMAP: is a general-purpose SfM and MVS pipeline with a graphical and command-line interface. In offers a wide range of featured for the reconstruction of ordered and unordered images (COLMAP, 2019).

The procedure of the dense point cloud generation is the same for all the above mentioned open-source software. Also, they have the possibility for the generation of 3D triangular mesh except for Visual SfM. In this study, the steps that were followed are about the production of the 3D point cloud. As opposed to Agisoft PhotoScan in which the user can apply "masks" on the images in order to restrict the case study object in open source software this tool is not available. Consequently, the produced dense point clouds have unnecessary information which was manually cleaned. Before the cleaning procedure point clouds were scaled according to the measured distances of the targets on the turntable in MeshLab freeware. Afterwards, the alignment procedure of the two point clouds was performed by picking common characteristic points on them in CloudCompare. Figure 7 presents the point cloud of the whole artefact after the alignment procedure.
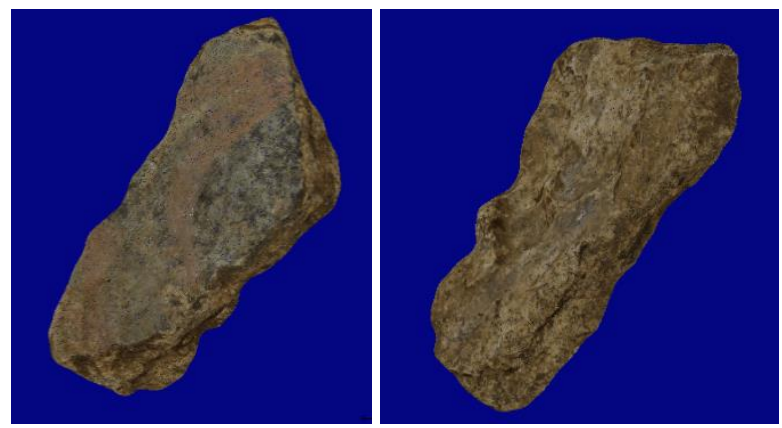

Figure 7: 3D point cloud of the artefact

Then the creation of the triangular mesh was performed. The mesh which was created in MeshLab with the Poisson surface reconstruction algorithm had unnecessary information, especially a plane that was arbitrarily created between the two parts (Figure 8). Hence, it was decided to use commercial software for the 3D mesh generation of the artefact. In this case study, the Geomagic Studio software was utilised. Figure 9 presents the final 3D meshes of the artefact.

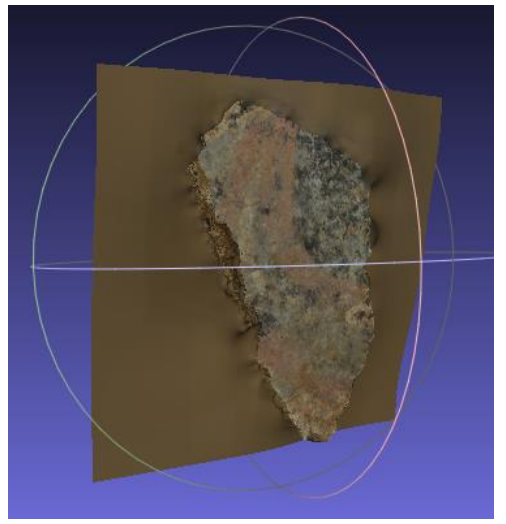

Figure 8: 3D triangular mesh with unnecessary information

\section{DISCUSSION}

The 3D models of fresco fragments that were produced present advantages over standard digital 2D photography which is mainly used by conservators. Particularly, the outcome of the procedure into Agisoft PhotoScan software provided a 3D model which is an exact digital replica of the authentic artefact. It is considered quite sufficient for the study of the fresco fragments without tampering with the fragile real object. Specifically, the colour and the texture of the painting surface, as well as the levelling coat of the plaster are extremely close to the real one.

As has already been highlighted, the 3D models of wall painting fragments produced can be beneficial, in conservation and scholarly study in general, because of their high accuracy and the accessibility that they enable. The potential uses of 3D models in cultural heritage preservation, their capabilities and suitability for conversation work and documentation are presented below. First of all, the creation of an accurate digital replica of each fragment is sufficient for their study by the experts, without stressing them by physical handling. So their examination can be contactless, totally non-destructive and can also be used as digital records. Moreover, each specialist is able to study the artefacts viewing them from different angles, without any time limitation nor physical presence in the museum. The important ability of accurately measuring every side of the object is also offered.

Examining the digital 3D model without texture, i.e. purely studying its geometric information, may lead to several conclusions about the fresco fragments manufacturing techniques and their state of preservation. Firstly, tracing the imprint of the support on which the undercoat of the mural was applied may be detected. This could assist the reconstruction procedure of the mural. Secondly, the 3D geometry may assist in detecting superficial losses or damages of the fragments over the years and in monitoring their condition of preservation

It is considered very important that small irregularities of the painted surface may be detected, which could reveal the painter's brushstrokes, just by a thorough examination. Moreover, an expert may be able to locate the technique of applying several layers of plaster of different consistency, one over the other, for achieving the finest painting surface. Figures 11 and 12 present all of these mentioned cases. Finally, the replicas can be utilized in a digital reconstruction of the Mycenaean wall paintings by digital matching of the fragments, in a museum exhibition, in education programme, etc. (Figure 9). (Katsichti, 2018). Also, an application was developed for PCs and smartphones which gives the ability to extract, in this case, colour information by clicking on the info point (Figure 10).

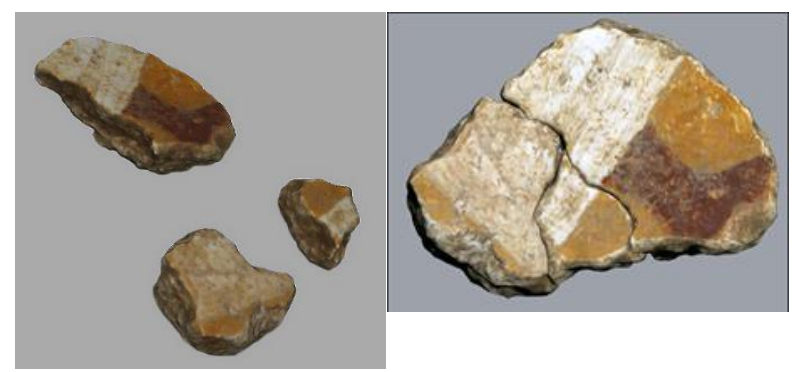

Figure 9: Manual digital reassembly of fragments 


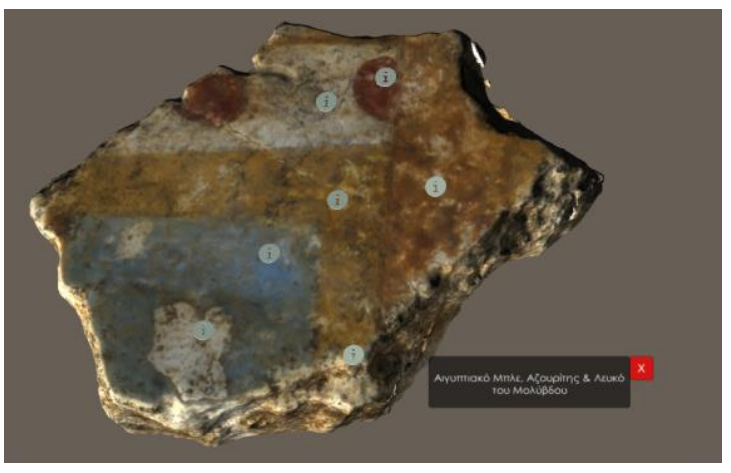

Figure 10: Application about colour information

Open source software were used for the creation of the dense point cloud of the same artefact S10. Table 1 presents the number of points that each software produced during the dense

\section{Agisoft Photoscan}

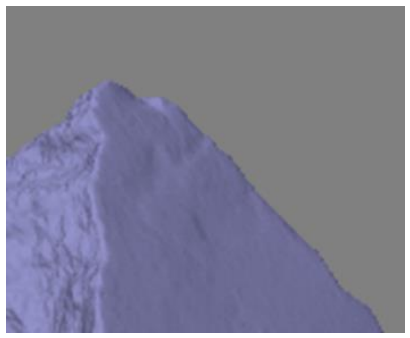

Visual SfM

Regard3D
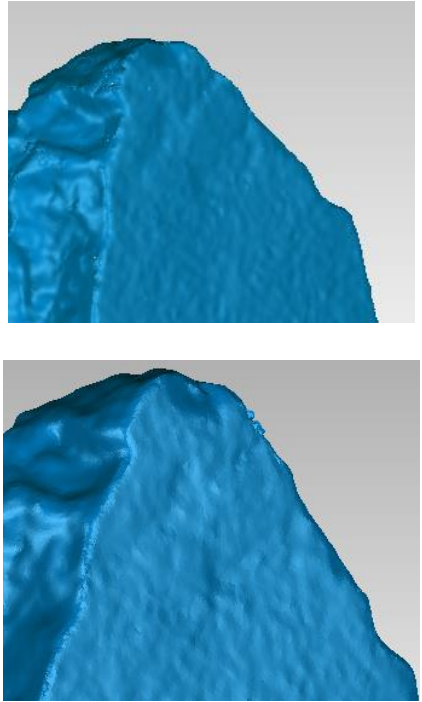

COLMAP

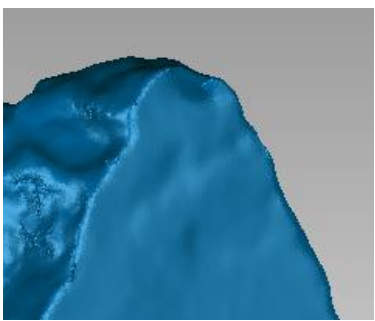

Irregularities of the painted surface point cloud generation, the number of points after the cleaning procedure and the number of triangles for each 3D mesh.

\begin{tabular}{|c|c|c|c|}
\hline Freeware & $\begin{array}{c}\text { Initial } \\
\text { num. of } \\
\text { points }\end{array}$ & $\begin{array}{c}\text { Num of } \\
\text { points } \\
\text { after } \\
\text { editing }\end{array}$ & $\begin{array}{c}\text { Num of } \\
\text { triangles }\end{array}$ \\
\hline Visual SfM & 1095792 & 387287 & 773394 \\
\hline Regard3D & 994653 & 331333 & 662447 \\
\hline COLMAP & 1271295 & 296405 & 589388 \\
\hline
\end{tabular}

Table 1: Number of points and faces and triangles for each model.

\section{ACKNOWLEDGEMENTS}

Authors would like to thank Adamantia Vasilogamvrou, emeritus director of antiquities at Hellenic Ministry of Culture, Dora Kondyli, assistant director, Nektarios Karadimas, trench supervisor and Yiota Menegaki, conservator.
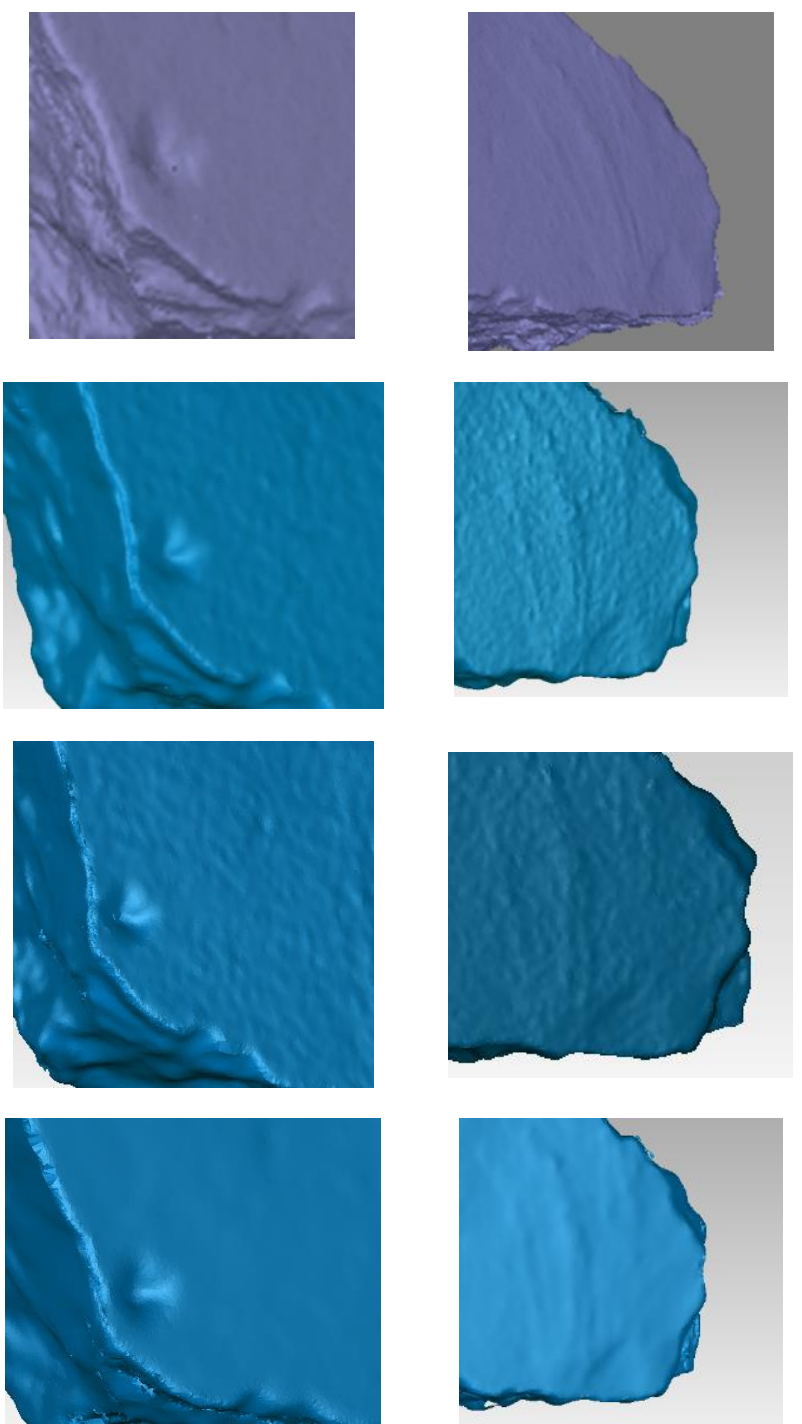

Mechanical damages
Painter's brushstrokes

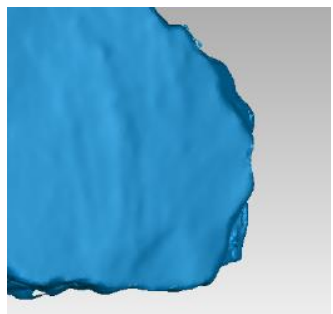

Figure 11: Different cases that a conservator can study applied in $3 \mathrm{~d}$ models created via commercial and open source software 


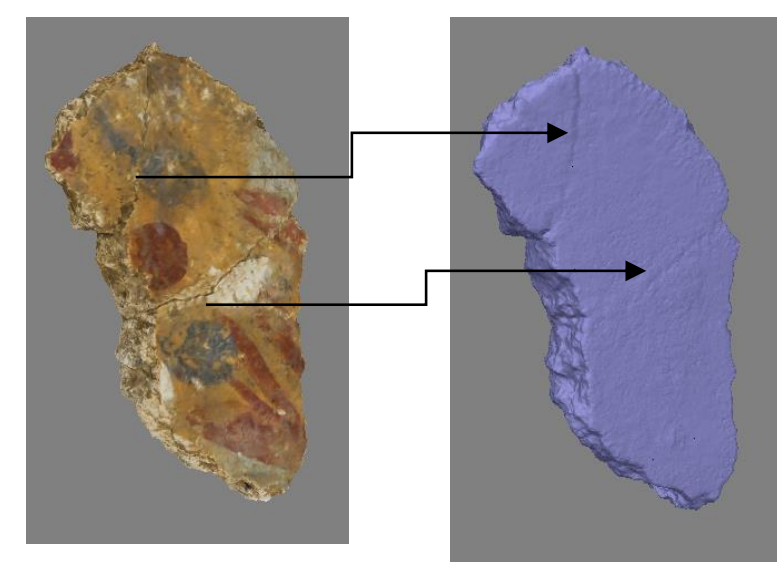

The 3D model of fresco fragment S8

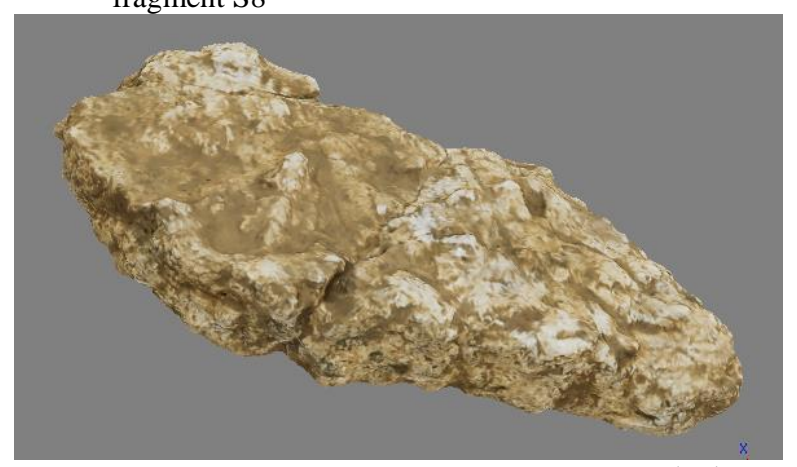

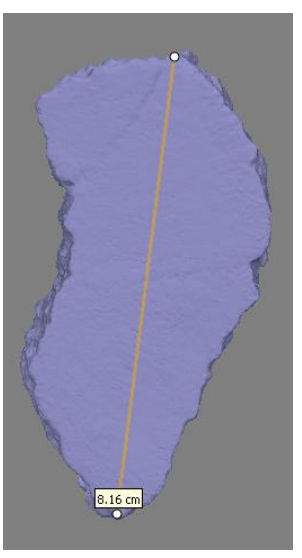

Accurate measurements at any desired direction

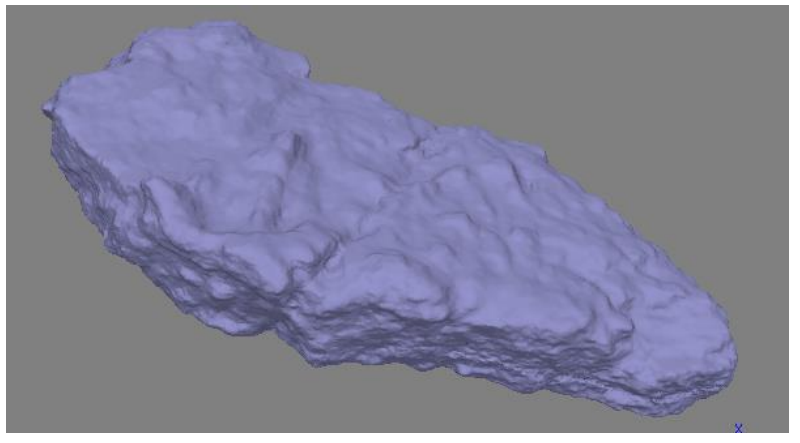

The layers of plaster located

Figure 12. Cases which conservator studies in 3D models

\section{REFERENCES}

Alcantarilla, P.F., Bartoli, A. and Davison, A.J., 2012, KAZE features. In European Conference on Computer Vision Springer, 214-227

Angheluță, L. M. and Rădvan, R., 2019, MACRO PHOTOGRAMMETRY FOR THE DAMAGE ASSESSMENT OF ARTWORK PAINTED SURFACES, Int. Arch. Photogramm. Remote Sens. Spatial Inf. Sci., XLII2/W15, 101-107, doi.org/10.5194/isprs-archives-XLII-2W15-101-2019

Ballarin, M., Balletti, C. and Vernier, P., 2018. REPLICAS IN CULTURAL HERITAGE: 3D PRINTING AND THE MUSEUM EXPERIENCE. Int. Arch. Photogramm. Remote Sens. Spatial Inf. Sci., XLII-2, 55-62, doi.org/10.5194/isprsarchives-XLII-2-55-2018

Clini, P., Frapiccini, N., Mengoni, M., Nespeca, R. and Ruggeri, L., 2016. SFM TECHNIQUE AND FOCUS STACKING FOR DIGITAL DOCUMENTATION OF ARCHAEOLOGICAL ARTIFACTS. Int. Arch. Photogramm. Remote Sens. Spatial Inf. Sci., XLI-B5, 230-236, doi:10.5194/isprsarchives-XLI-B5-229-2016

COLMAP, 2019 General purpose SfM and MVS freeware. https://colmap.github.io/ (18 October 2019)

Evgenikou V. and Georgopoulos, A., 2015. INVESTIGATING 3D RECONSTRUCTION METHODS FOR SMALL ARTIFACTS. Int. Arch. Photogramm. Remote
Sens. Spatial Inf. Sci., XL-5/W4, 101-108, doi:10.5194/isprsarchives-XL-5-W4-101-2015

Foldio $360^{\circ}, 2019$ A Smart turntable to create 360 images, http://orangemonkie.com/foldio360/ (16 October 2019)

Fregonese, L., Giordani, N., Adami, A., Bachinsky, G., Taffurelli, L., Rosignoli, O., and Helder, J., 2019, PHYSICAL AND VIRTUAL RECONSTRUCTION FOR AN INTEGRATED ARCHAEOLOGICAL MODEL: 3D PRINT AND MAQUETTE, Int. Arch. Photogramm. Remote Sens. Spatial Inf. Sci., XLII-2/W15, 481-487, doi.org/10.5194/isprsarchives-XLII-2-W15-481-2019

Furukawa, Y. and Ponce, J., 2009. Accurate, dense, and robust multiview stereopsis. IEEE transactions on pattern analysis and machine intelligence, 32(8), 1362-1376

Gajski, D., Solter, A. and Gašparović, M., 2016. APPLICATIONS OF MACRO PHOTOGRAMMETRY IN ARCHAEOLOGY. Int. Arch. Photogramm. Remote Sens. Spatial Inf. Sci., XL1-B5, 263-266, doi:10.5194/isprsarchivesXLI-B5-263-2016

Gallo, A., Muzzupappa, M. and Bruno, F., 2014. 3D reconstruction of small sized objects from a sequence of multifocused images. Journal of Cultural Heritage, 15(2), 173-182.

Gattet, E., Devogelaere, J., Raffin, R., Bergerot, L., Daniel, M., Jockey, P. and De Luca, L., 2015. A versatile and low-cost $3 \mathrm{D}$ acquisition and processing pipeline for collecting mass of archaeological findings on the field. Int. Arch. Photogramm. Remote Sens. Spatial Inf. Sci., XL-5/W4, 299-305, doi:10.5194/isprsarchives-XL-5-W4-299-2015 
Guidi, G., Gonizzi, S. and Micoli, L., 2014. Image preprocessing for optimizing automated photogrammetry performances. ISPRS Ann. Photogramm. Remote Sens. Spatial Inf. Sci, II-5, 145-152, doi:10.5194/isprsannals-II-5145-2014

Hosseininaveh, A., Yazdan, R., Karami, A., Moradi, M. and Ghorbani, F., 2015. A low-cost and portable system for 3D reconstruction of texture-less objects. Int. Arch. Photogramm. Remote Sens. Spatial Inf. Sci., XL-1/W5, 327-332, doi:10.5194/isprsarchives-XL-1-W5-327-2015

Hosseininaveh, A., Sargeant, B., Erfani, T., Robson, S., Shortis, M., Hess, M. and Boehm, J., 2014. Towards fully automatic reliable 3D acquisition: From designing imaging network to a complete and accurate point cloud. Robotics and Autonomous Systems, 62(8), 1197-1207, dx.doi.org/10.1016/j.robot.2014.04.001

Katsichti, V., 2018. Application of spectroscopic techniques and passive 3D digitization method to fragments of Mycenaean frescoes and offering table of Ayios Vasileios site in Laconia, Master Thesis, University of Aegean, Department of Mediterranean Studies, Postgraduate programme "Applied Archaeological Sciences". (In Greek)

Kontogianni, G., Lindstaedt, M., Kersten, T. P., and Georgopoulos, A., 2019 EVALUATING THE EFFECT OF USING MIRRORS IN 3D RECONSTRUCTION OF SMALL ARTEFACTS, Int. Arch. Photogramm. Remote Sens. Spatial Inf. Sci., XLII-2/W15, 633-638, doi.org/10.5194/isprsarchives-XLII-2-W15-633-2019

Kontogianni, G., Thomaidis, A.T., Chliverou, R. and Georgopoulos, A., 2018. Exploiting Mirrors in 3d Reconstruction of Small Artefacts. Int. Arch. Photogramm. Remote Sens. Spatial Inf. Sci., XLII-2, 531-537, doi.org/10.5194/isprs-archives-XLII-2-531-2018

Kontogianni, G., Chliverou, R., Koutsoudis, A., Pavlidis, G. and Georgopoulos, A., 2017. ENHANCING CLOSE-UP IMAGE BASED 3D DIGITISATION WITH FOCUS STACKING. Int. Arch. Photogramm. Remote Sens. Spatial Inf. Sci., XLII-2/W5, 421-425, doi.org/10.5194/isprsarchives-XLII-2-W5-421-2017

Kontogianni, G., Chliverou, R., Koutsoudis, A., Pavlidis, G. and Georgopoulos, A., 2017. Investigating the effect of focus stacking on sfm-mvs algorithms. Int. Arch. Photogramm. Remote Sens. Spatial Inf. Sci., XLII-2/W3, 385-389, doi.org/10.5194/isprs-archives-XLII-2-W3-385-2017

Koutsoudis, A., Ioannakis, G., Vidmar, B., Arnaoutoglou, F. and Chamzas, C., 2015. Using noise function-based patterns to enhance photogrammetric 3D reconstruction performance of featureless surfaces. Journal of Cultural Heritage, 16(5), 664670 .

Koutsoudis, A., Vidmar, B. and Arnaoutoglou, F., 2013. Performance evaluation of a multi-image $3 \mathrm{D}$ reconstruction software on a low-feature artefact. Journal of Archaeological Science, 40(12), 4450-4456.

Lachat, E., Landes, T. and Grussenmeyer, P., 2017. PERFORMANCE INVESTIGATION OF A HANDHELD 3D SCANNER TO DEFINE GOOD PRACTICES FOR SMALL ARTEFACT 3D MODELING. Int. Arch.
Photogramm. Remote Sens. Spatial Inf. Sci., XLII-2/W5, 437434, doi:10.5194/isprs-archives-XLII-2-W5-427-2017

Marshall, M. E., Johnson, A. A., Summerskill, S. J., Baird, Q., and Esteban, E., 2019, AUTOMATING PHOTOGRAMMETRY FOR THE 3D DIGITISATION OF SMALL ARTEFACT COLLECTIONS, Int. Arch. Photogramm. Remote Sens. Spatial Inf. Sci., XLII-2/W15, 751-757, doi.org/10.5194/isprs-archives-XLII-2-W15-7512019

Menna, F., Nocerino, E., Morabito, D., Farella, E.M., Perini, M. and Remondino, F., 2017. An Open Source Low-Cost Automatic System for Image-Based 3d Digitization. Int. Arch. Photogramm. Remote Sens. Spatial Inf. Sci., XLII-2/W8, 155162, doi.org/10.5194/isprs-archives-XLII-2-W8-155-2017

MeshLab, 2019 Open source system for processing \& editing 3D triangular meshes, http://www.meshlab.net/ (20 October 2019)

Nicolae, C., Nocerino, E., Menna, F. and Remondino, F., 2014. Photogrammetry applied to problematic artefacts. Int. Arch. Photogramm. Remote Sens. Spatial Inf. Sci., XL-5, 451-456. doi:10.5194/isprsarchives-XL-5-451-2014

PAE, 2010. Praktika tes en Athenais Archaiologikes Hetaireias. 65-80, (in Greek)

Papadaki, A.I., Agrafiotis, P., Georgopoulos, A. and Prignitz, S., 2015. ACCURATE 3D SCANNING OF DAMAGED ANCIENT GREEK INSCRIPTIONS FOR REVEALING WEATHERED LETTERS. Int. Arch. Photogramm. Remote Sens. Spatial Inf. Sci., XL-5/W4, 237-243, doi:10.5194/isprsarchives-XL-5-W4-237-2015

Regard 3D, 2019 A free and open source structure-frommotion program, http://www.regard3d.org/ (18 October 2019).

Ritz, M., Langguth, F., Scholz, M., Goesele, M. and Stork, A., 2012. High resolution acquisition of detailed surfaces with lens-shifted structured light. Computers \& Graphics, 36(1), 16-27.

Rodríguez Miranda, Á., Valle Melón, J. M., Torices, A., Lostado, R., Navarro, P., Elorriaga Agirre, G., Korro Bañuelos, J., and Zornoza-Indart, A., 2019, 3D DIGITIZATION OF COMPLEX EXHIBITION ITEMS (MOUNTED SKELETONS OF DINOSAURS) AND GENERATION OF VIRTUAL REPLICAS FOR BIOMECHANICAL STUDIES, Int. Arch. Photogramm. Remote Sens. Spatial Inf. Sci., XLII-2/W15, 1015-1021, doi.org/10.5194/isprs-archives-XLII-2-W15-1015-2019

Sapirstein, P., 2018. A high-precision photogrammetric recording system for small artifacts. Journal of Cultural Heritage, 31, 33-45, doi.org/10.1016/j.culher.2017.10.011

Soile, S., Adam, K., Ioannidis, C. and Georgopoulos, A., 2013. Accurate 3D textured models of vessels for the improvement of the educational tools of a museum. Int. Arch. Photogramm. Remote Sens. Spatial Inf. Sci., XL-5/W1, 211-217. doi.org/10.5194/isprsarchives-XL-5-W1-211-2013, 2013

Visual SfM, 2019 A Visual Structure from Motion System, http://ccwu.me/vsfm/ (18 October 2019) 
The International Archives of the Photogrammetry, Remote Sensing and Spatial Information Sciences, Volume XLII-2/W17, 2019

6th International Workshop LowCost 3D - Sensors, Algorithms, Applications, 2-3 December 2019, Strasbourg, France

Wang, Z., Fan, B. and Wu, F., 2011, Local intensity order pattern for feature description. In 2011 International Conference on Computer Vision, 603-610.

XRite Color Checker, 2019 Chromatic scale, https://www.xrite.com/categories/calibration-

profiling/colorchecker-classic (16 October 2019) 